\title{
THE TYPES OF FRACTURE OF THE PELVIS ASSOCIATED WITH URETHRAL RUPTURE AND THEIR RELATIVE FREQUENCY
}

By H. S. TRAFFord, F.R.C.S.

Casualty Surgeon, North Staffordshire Royal Infirmary, Stoke-on-Trent

Recently a review has been made at the North Staffordshire Royal Infirmary of 37 cases of fracture of the pelvis and rupture of the posterior urethra in an attempt to ascertain first the frequency of this injury, and secondly to attempt to determine which fractures of the pelvis are likely to be complicated by this injury to the lower urinary tract. The majority of these accidents occurred in the period $1943-55$.

\section{Relative Frequency of the Injury}

The period $1945-55$ is taken as illustrative for this purpose, and during this period it was found that there were about 28,000 emergency surgical admissions to the North Staffordshire Royal Infirmary. During the same period 29 ruptures of the urethra were seen. This includes both anterior and posterior urethral ruptures. This suggests that in a busy industrial area just under $I$ in I,000 surgical emergency admissions is likely to be a rupture of the urethra.

Next, what is the incidence of this injury in all fractures of the pelvis? The only comparable figure in the literature is that given by Uhle and Erb (1944) and they say the incidence is I to I I per cent., which is a very rough estimate. In the ten-year period cited above there were $4 \mathrm{I} 2$ fractures of the pelvis admitted to this hospital, amongst which were 19 associated with rupture of the urethra. The true incidence in this experience, therefore, is 4 to 6 per cent. This figure applies entirely, of course, to damage to the posterior urethra.

\section{Aetiology}

Rupture of the posterior urethra is usually associated with fractures of the pelvis, and the present series of 37 cases of this injury was entirely confined to this accident. The injury occurs therefore most frequently in mining or industrial areas, such as the district from which this series has been taken. All types of crushing injuries occurring in miners, railway workers, and as a result of road accidents are likely to be complicated by injury to this part of the lower urinary tract. Amongst the 37 cases quoted the following causes were found: 14 were due to road accidents I 5 to pit accidents; and 8 to miscellaneous crush injuries, including railway accidents.

\section{Types of Fracture}

It is now proposed to analyse the fractures of the pelvis to see if there is any common factor $\cong$ which predisposes to urethral injury, and to compare and contrast these fractures with an independent series of 37 pelvic fractures which had 은 no evidence of any urethral injury. The last group of cases mentioned has been taken at random from the orthopaedic practice of a busy general hospital during the last three years.

In the description of lesions at the symphysis pubis distinction is drawn between separation of the two halves, in which horizontal alignment 8 maintained, and displacement, in which some separation, but also loss of alignment in both planes occurs. In the complicated cases the following damage to the pelvic ring was seen: 25 cases had marked displacement of the symphysis pubis associated with a variety of fractures elsewhere in the pelvic ring; 7 cases had no displacement, but considerable separation of the symphysis pubis and fractures through a sacro-iliac joint. The remaining 5 cases had no displacement or separation of the symphysis, but had fractures of both pubic rami, on one or other side, close to the symphysis, and in each case loose spicules of bone were apparent, which presumably were the cause of the damage to the urethra.

By contrast 37 uncomplicated fractures of the pelvis showed: Only I I cases with separation or displacement of the symphysis pubis, and in no instance could this be called any more than moderate ; 8 cases had fractures through the sacro- $\sigma$ iliac joints, or the blade of the ileum; 6 cases had $N$ fractures of the acetabulum; 22 cases had a frac- N ture of both pubic rami on one side, and 3 cases had a fracture of one pubic ramus only. Many of the cases had a combination of more than one $\underset{\mathbb{D}}{\overparen{D}}$ of the above fractures, which accounts for the $\stackrel{\infty}{+}$ total number of fractures coming to more than 0 the total 37 cases. 


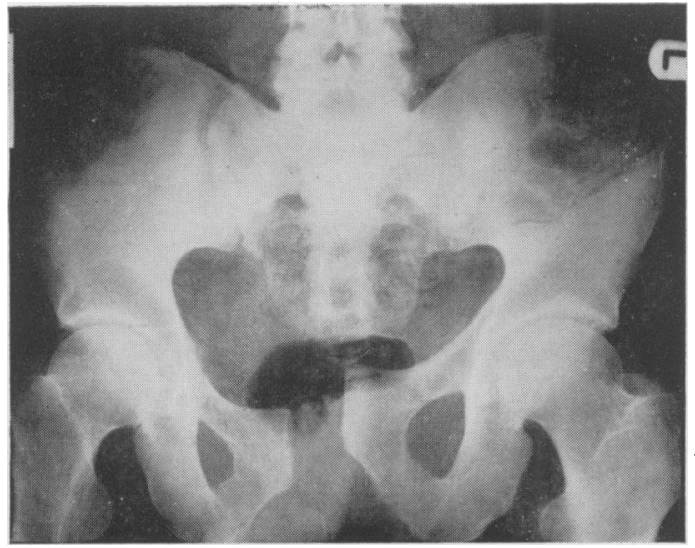

FIG. I.-Typical pelvic fracture complicated by urethral injury, showing displacement of the symphysis pubis.

\section{Conclusion}

Certain quite dogmatic conclusions can now be drawn from comparison of these two series of cases:

(a) The commonest uncomplicated fracture of the pelvis appears to be that of fracture of both pubic rami on one or other side.

(b) Rupture of the posterior urethra is associated with the more severe types of pelvic fracture, particularly those showing gross injury to the symphysis pubis and pubic rami.

(c) Rupture of the urethra is most likely to occur when there is much displacement of the two halves of the symphysis pubis, in which injury, both a stretching and a shearing force is exerted on the organ. If rupture is associated with simple separation of the symphysis pubis only, then such separation must apparently be quite wide.

(d) In a smaller proportion of fractures, rupture of the urethra may occur without any disruption of the symphysis pubis, and is then due to damage by spicules of bones, produced by fractures of the pubic rami, close to their junction with the symphysis pubis.

\section{Acknowledgment}

I am grateful to the general and orthopaedic

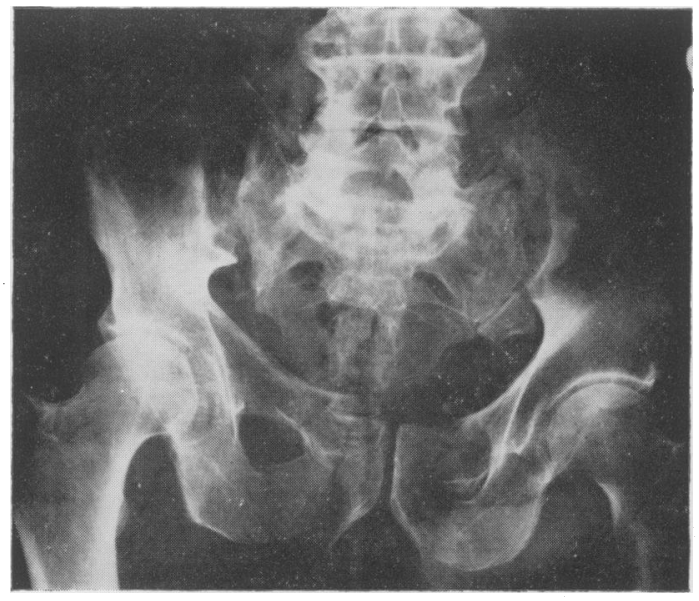

FIG. 2.-Uncomplicated multiple fractures of the pelvis, in which the symphysis pubis is not disturbed.

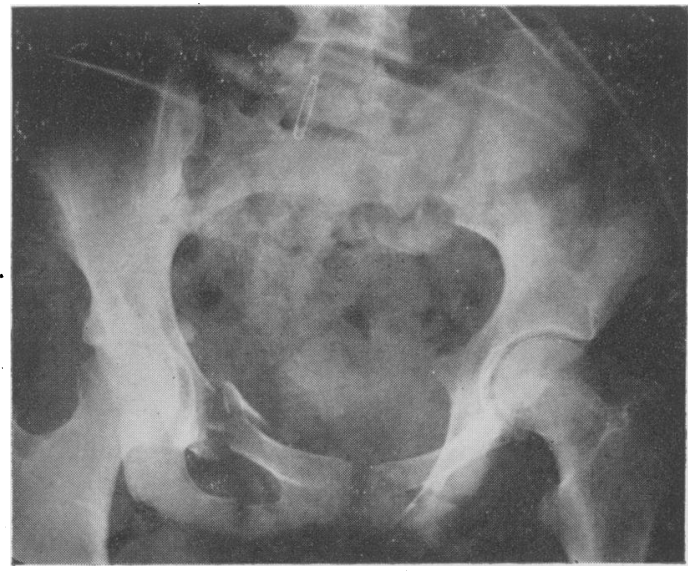

FIG. 3.-Another uncomplicated pelvic fracture with no displacement of the symphysis pubis.

surgeons of the North Staffordshire Royal Infirmary for allowing me access to the clinical material quoted, to the radiological staff of the same Infirmary for the pelvic radiographs, and the Department of Clinical Photography for the prints of these.

\section{BIBLIOGRAPHY}

KAUFMANN, J. J. (195I), $\mathcal{F}_{\text {. Bone }} \mathfrak{F}_{t}$ Surg., 33A, 1017. UHLE, C. W., and ERB, R. H. (1944), Amer. $\mathscr{\Im}$. Urol., 52, 43.

Continued from page 655-N. Nagaratnam, M.B., B.S., and C. S. W. Kannangara, M.B., B.S.

\section{Acknowledgments}

We wish to thank Professor W. A. E. Karunaratne for his valuable criticism and encouragement and Dr. L. N. Bartholomeuz for the use of his case.

\section{BIBLIOGRAPHY}

CROMAR, C. D. L., and DOCKERTY, M. B. (194I), Proc. Mayo Clin., 16, 775 .

CUTLER, M. (1949), Brit. med. F., i, 94.

RODMAN, J. S., and INGLEBY, H. (1930), Ann, Surg., rog, 921. 